\title{
Orbital Dermoid Cyst
}

\author{
CAROL M. LANE, W. W. EHRLICH and J. E. WRIGHT \\ London
}

\begin{abstract}
Summary
Over a thirteen year period forty patients underwent surgery to remove an orbital dermoid cyst. Cysts which became manifest after the age of three years were deeper and larger than most that were noted before that age. Three out of four epidermoid cysts appeared after the age of 17 years and had an intracranial component. The majority of cysts showed histological evidence of leakage and associated inflammation. It is our view that dermoid cysts should be totally excised because they gradually enlarge and cause inflammation and scarring in adjacent structures.
\end{abstract}

Dermoid cyst is the commonly used clinical term for benign cystic teratoma, ${ }^{1}$ a choristoma derived from sequestration of surface ectoderm into underlying mesenchyme along embryonic lines of closure. ${ }^{2}$ Both dermoids and epidermoids are lined by keratinised stratified squamous epithelium and have a fibrous wall. A dermoid has dermal appendages (Fig. 1), whereas an epidermoid has none. A conjunctival dermoid is distinguished by a non-keratinising epithelium and dermal appendages. ${ }^{3,4}$

The majority of dermoid cysts seen in ophthalmic practice are superficial and present in early childhood as discrete swellings in the brow or eyelid. Deep orbital dermoid cysts are infrequently seen, less easily diagnosed and require more extensive surgery. ${ }^{5}$ Poorly planned, delayed or incomplete removal of either of these types of lesion may result in severe inflammation and permanent functional impairment. The surgical outcome of a series of dermoid cysts was assessed in relation to the clinical and histopathological features.

\section{Patients and Methods}

A consecutive series of 40 cases with a histological diagnosis of orbital dermoid cyst was analysed. All patients attended the Orbital Clinic at Moorfields Eye Hospital and underwent surgery between 1973 and 1986. The majority of patients had been referred from other practices, so there was a bias towards complex cases. In a few diagnosis of dermoid cyst was not suspected prior to surgery. Thirty-seven had no previous surgical procedure and the remaining three had marked orbital inflammation, with fistula formation in two cases, following incomplete excision of a cyst.

Diagnostic investigations included plain and tomographic X-rays with computerised tomography and ultrasound scanning in selected cases. Surgery was undertaken to excise the entire cyst or completely remove the epithelial lining, except in one case in which only the keratin core of a cyst was extracted. Twenty-eight patients had an anterior orbitotomy, approaching the lesion through the orbital septum in most cases. Ten patients had a lateral orbitotomy, eight with removal of bone, and two were referred for anterior craniotomy. All histopathological material was examined at the Institute of Ophthalmology or the Institute of Neurology. Follow-up was 12 years to six months.

\section{Results}

Twenty-two patients were male and 18 were 


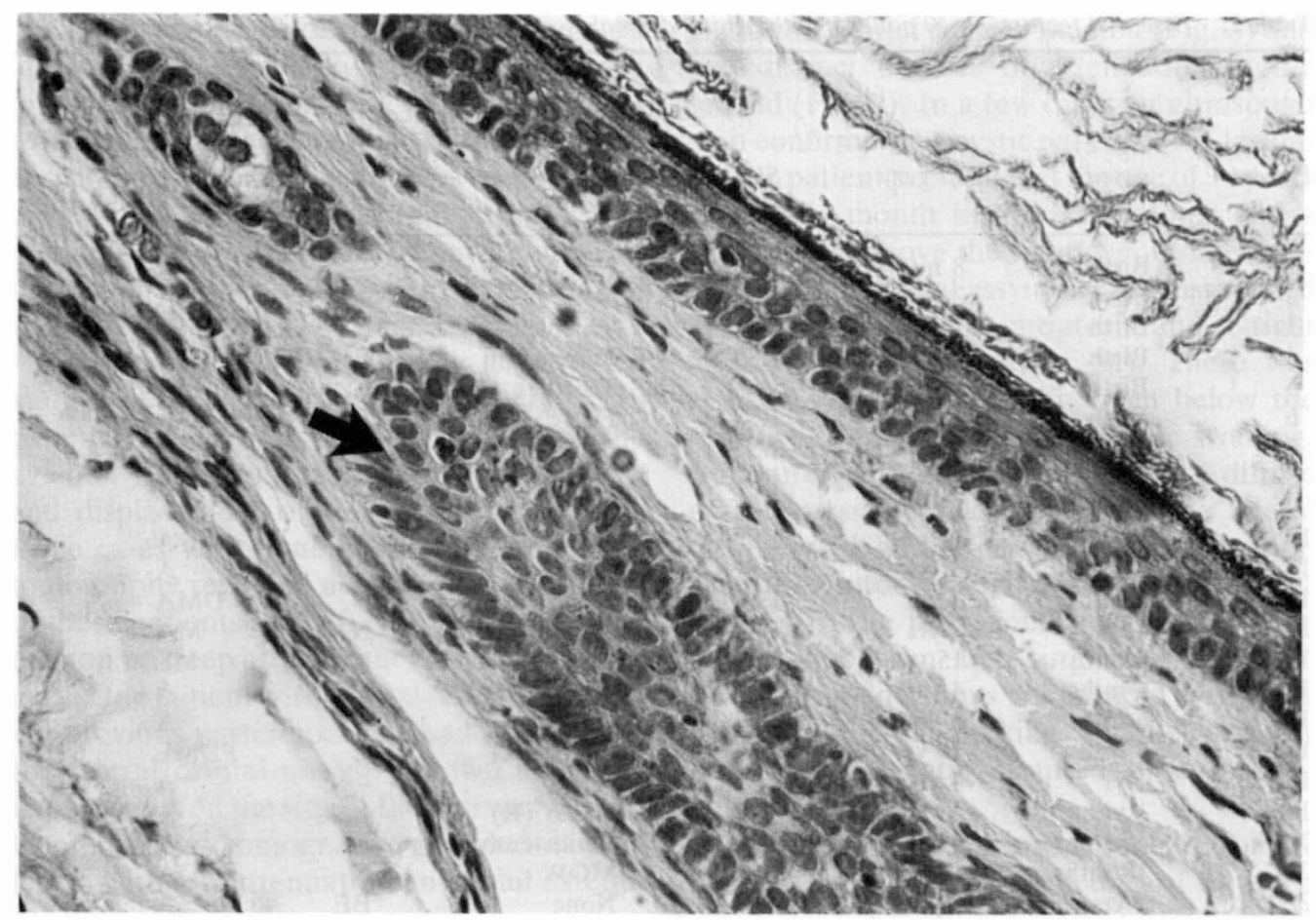

Fig. 1. Light micrograph of H\&E stained section through the wall of a typical dermoid cyst from patient No. 1 . The lining is stratified squamous keratinising epithelium and a hair follicle is present in the wall (arrow).

female. Table I shows the essential clinical and surgical features. The cyst was noted at birth in 6 patients ( 15 per cent), by the age of 6 months in 17 patients (42.5 per cent) and before the age of 12 years in 30 patients ( 75 per cent), with a median age of 18 months. In one the age of onset was recorded as 'In early childhood'. Only one patient (No. 32) gave a history of trauma, in the form of depressed skull fracture at the age of one year.

The most common site was the left superotemporal quadrant, the site of the cyst in 12 patients. The left orbit was involved in 24 patients and the right in sixteen. Eighteen occurred superonasally, 18 superotemporally, 3 laterally and only one inferotemporally.

Thirty-seven patients noticed a gradually enlarging mass and two only noticed increasing proptosis. One patient (No. 17) had an episode of proptosis at the age of six months and was then assymptomatic until the age of 17 years, when she noted a mass. In one case (No. 39) the cyst became infected and rapid onset of pain and swelling occurred overnight.
Swelling became more prominent on crying in four patients and on stooping in one patient. Seven patients complained of pain or tenderness. All these cysts had histological evidence of chronic inflammation. Two patients (Nos. $17 \& 36$ ) with a history of incomplete excision of the cyst experienced repeated discharge of cystic contents through a sinus to the conjunctiva in one case and the skin in a second.

Two children had a history of strabismus. Patient No. 4 was hypermetropic with a right amblyopia and 15 dioptres of esotropia. He had multiple associated abnormalities, including a preauricular skin tag, pectus excavatum and a duplex kidney, suggestive of Goldenhar's syndrome. His brother also had a dermoid cyst. Patient No. 13 had surgery for strabismus at the age of eight months and a ' $V$ ' pattern exophoria. Eight patients, all aged 21 years or more, experienced diplopia which was related to ocular displacement.

When palpated the orbital mass was described as mobile in 13 cases and fixed in the remainder. The texture was firm or rubbery 
Table I: Essential features in 40 patients with orbital dermoids

\begin{tabular}{|c|c|c|c|c|c|c|c|}
\hline Patient & $\begin{array}{l}\text { Age cyst } \\
\text { noted }\end{array}$ & $\begin{array}{l}\text { Age at } \\
\text { surgery }\end{array}$ & Site & Attachment & $X r$ & $\begin{array}{l}\text { Proptosis } \\
\text { disp globe } \\
\text { mobility } \\
\text { approach }\end{array}$ & $\begin{array}{l}V a \\
C / E\end{array}$ \\
\hline 1 & Birth & $8 \mathrm{mths}$ & RSTQ & FZS & - & MA & \\
\hline 2 & Birth & $2 \mathrm{yrs}$ & LSTQ & None & - & MA & \\
\hline 3 & Birth & $7 \mathrm{yrs}$ & RSNQ & Trochlea & $\mathbf{N}$ & MA & \\
\hline 4 & Birth & $7 \mathrm{yrs}$ & RSTQ & Periosteum & $\mathrm{BE}$ & MA & $6 / 12$ \\
\hline 5 & Birth & 8 yrs & LSNQ & Trochlea & $\mathbf{N}$ & MA & \\
\hline 6 & Birth & $18 \mathrm{yrs}$ & RSTQ & FZS & $\mathrm{BE}$ & PDA & \\
\hline 7 & 2 wks & 2 yrs & LSTQ & None & $\mathrm{N}$ & MA & \\
\hline 8 & $2 \mathrm{wks}$ & $2 \mathrm{yrs}$ & RSTQ & Tarsus & - & MA & \\
\hline 9 & $1 \mathrm{mth}$ & $22 \mathrm{mths}$ & LSTQ & None & - & MA & \\
\hline 10 & $2 \mathrm{mths}$ & $14 \mathrm{yrs}$ & LSNQ & MOW & $\mathbf{N}$ & A & \\
\hline 11 & $3 \mathrm{mths}$ & 3 yrs & RSNQ & Trochlea & - & A & \\
\hline 12 & $3 \mathrm{mths}$ & 3 yrs & LSTQ & None & $\mathbf{N}$ & DMA & \\
\hline 13 & $4 \mathrm{mths}$ & 3 yrs & LSTQ & None & $\mathbf{N}$ & MA & \\
\hline 14 & $4 \mathrm{mths}$ & $15 \mathrm{yrs}$ & LSTQ & LF & $\mathrm{N}$ & ML & $\mathrm{C}$ \\
\hline 15 & $6 \mathrm{mths}$ & 4 yrs & LSNQ & None & $\mathrm{BE}$ & A & \\
\hline 16 & $6 \mathrm{mths}$ & 6 yrs & LSTQ & ST & $\mathrm{N}$ & A & \\
\hline 17 & $6 \mathrm{mths}$ & $30 \mathrm{yrs}$ & LSTQ & Globe $(\mathrm{R})$ & $\mathrm{E}$ & PDML & $6 / 18$ \\
\hline 18 & $1 \mathrm{yr}$ & 4 yrs & LSNQ & None & - & A & E \\
\hline 19 & $1 \mathrm{yr}$ & $4 \mathrm{yrs}$ & RSNQ & MOW (R) & $\mathrm{N}$ & A & $6 / 60$ \\
\hline 20 & $15 \mathrm{mths}$ & 4 yrs & RSNQ & Periosteum & - & A & \\
\hline 21 & $18 \mathrm{mths}$ & $17 \mathrm{yrs}$ & LSNQ & MOW & $\mathrm{N}$ & DA & \\
\hline 22 & 2 yrs & 5 yrs & RSNQ & None & $\mathrm{BE}$ & A & \\
\hline 23 & 3 yrs & 3 yrs & RSNQ & MOW & $\mathrm{N}$ & A & $6 / 9$ \\
\hline 24 & 3 yrs & 41 yrs & LSTQ & FZS & $\mathrm{BE}$ & PDL & \\
\hline 25 & Child & $34 \mathrm{yrs}$ & LSNQ & Roof (R) & $\mathrm{N}$ & PDT & \\
\hline 26 & 5 yrs & $22 \mathrm{yrs}$ & LSNQ & Apex & $\mathrm{BE}$ & PDA & $6 / 12 \mathrm{C}$ \\
\hline 27 & 7 yrs & $14 \mathrm{yrs}$ & LITQ & Apex (R) & $\mathrm{BE}$ & PDA & \\
\hline 28 & 8 yrs & 9 yrs & RLAT & LOW & $\mathrm{BE}$ & PDL & \\
\hline 29 & $9 \mathrm{yrs}$ & $14 \mathrm{yrs}$ & LSTQ & Apex & $\mathbf{N}$ & PDL & \\
\hline 30 & $11 \mathrm{yrs}$ & 44 yrs & RSTQ & FZS & $\mathrm{BE}$ & PDL & \\
\hline 31 & $13 \mathrm{yrs}$ & $24 \mathrm{yrs}$ & LSNQ & Apex (R) & $\mathrm{BE}$ & MA & \\
\hline 32 & $17 \mathrm{yrs}$ & $21 \mathrm{yrs}$ & RSNQ & FZS (R) & $\mathrm{BE}$ & PDT & $6 / 36 \mathrm{E}$ \\
\hline 33 & $17 \mathrm{yrs}$ & 22 yrs & LSTQ & LOW $(\mathrm{R})^{*}$ & $\mathbf{N}$ & $\mathrm{L}$ & \\
\hline 34 & 22 yrs & 22 yrs & LSNQ & MOW (R) & $\mathrm{BE}$ & PDA & \\
\hline 35 & $25 \mathrm{yrs}$ & $43 \mathrm{yrs}$ & RSNQ & Trochlea & $\mathrm{BE}$ & DA & C \\
\hline 36 & 27 yrs & 32 yrs & LLAT & LF $(\mathrm{R})^{*}$ & $\mathrm{BE}$ & DL & \\
\hline 37 & $28 \mathrm{yrs}$ & 31 yrs & LSNQ & None & $B E$ & PDA & \\
\hline 38 & 30 yrs & 32 yrs & LSTQ & FZS & $\mathrm{BE}$ & PDL & $6 / 9 \quad \mathrm{E}$ \\
\hline 39 & 49 yrs & 49 yrs & RSTQ & FZS (R) & $\mathrm{BE}$ & DL & \\
\hline 40 & 89 yrs & 90 yrs & RSNQ & FZS (R) & $\mathrm{BE}$ & PDA & $6 / 36 \mathrm{E}$ \\
\hline
\end{tabular}

Index to Table I. $\quad$ R Right; L Left; STQ Superotemporal quadrant; SNQ Superonasal quadrant; ITQ Inferonasal quadrant; LAT Lateral orbit; FZS Frontozygomatic suture; LOW Lateral orbital wall; MOW Medial orbital wall; LF Lacrimal fossa; ST Superotemporal rim; A Anterior orbitotomy; L Lateral orbitotomy; $T$ Transfrontal craniotcmy; $(R)$ Ruptured at surgery; * Previous partial excision; $N$ Normal; E Exostosis; BE Bone erosion; $P$ Proptosed globe; D Displaced globe; C Conjunctival dermoid; E Epithermoid; M Mobile cyst.

(19 cases), soft or cystic (17 cases), craggy (1 case) or diffuse ( 3 cases). The size varied from $1 \mathrm{~cm}$ diameter up to more than $3 \mathrm{~cm}$. The globe was displaced in 19 cases, of which 14 had proptosis. Ptosis was present in eight patients, six of whom had a cyst in the super- onasal quadrant. One of these patients (No. 22) had congenital ptosis, worse on the side of the cyst.

Reduced visual acuity in eight cases was attributable to amblyopia in two (No. $4 \&$ No. 17), compound astigmatism in two (No. $19 \&$ 
No. 26), optic nerve or pathway compression in two (Nos. $32 \& 40$ ) and choroidal folds in a further two cases (Nos. $23 \& 38$ ). Two patients with normal visual acuity had optic disc swelling, and a further two patients with proptosis complained of reduced visual acuity while reading. Both were found to have defects of the orbital roof with visible dura at the time of surgery.

Bone erosion, with a sharply demarcated margin (Fig. 2), was seen on X-ray in 18 patients, all of whom were examined after the age of 4 years. Proptosis was present in 11/18 and displacement of the globe in 14/18. In three cases with bone erosion computerised tomography revealed no abnormality. In one of these patients and a further two with bone erosion no deep attachment was found at surgery. One patient with orbital cellulitis following previous partial excision had exostosis of the lateral orbital margin. In two cases the frontal sinus on the side of the cyst was absent. Computerised tomography revealed a nasal lesion with low attenuation and a tail extend- ing to the orbital apex in the first (Fig. 3) and two distinct degrees of attenuation in the second (Fig. 4). In a few cases an ultrasound scan confirmed the cystic nature of the lesion.

One patient presented at the age of 90 years with a six month history of diplopia and a tender mass above the right eye. On examination marked facial assymetry was associated with $14 \mathrm{~mm}$ of right proptosis and a right visual acuity of $6 / 36$ (Fig. 5a). There was reduced sensation to light touch below the right eyebrow and right optic disc swelling. Computerised tomography showed a diffuse orbital mass with destruction of the lateral orbital wall and areas of low attenuation extending into the right middle cranial fossa (Fig. 5b). The provisional diagnosis was an orbital neoplasm but surgical exploration revealed an enormous epidermoid cyst, filled with keratin. Debulking of the cyst by removal of keratin resulted in a marked improvement.

Age at the time of surgery ranged from 90 years to 8 months, with a median of 14 years.

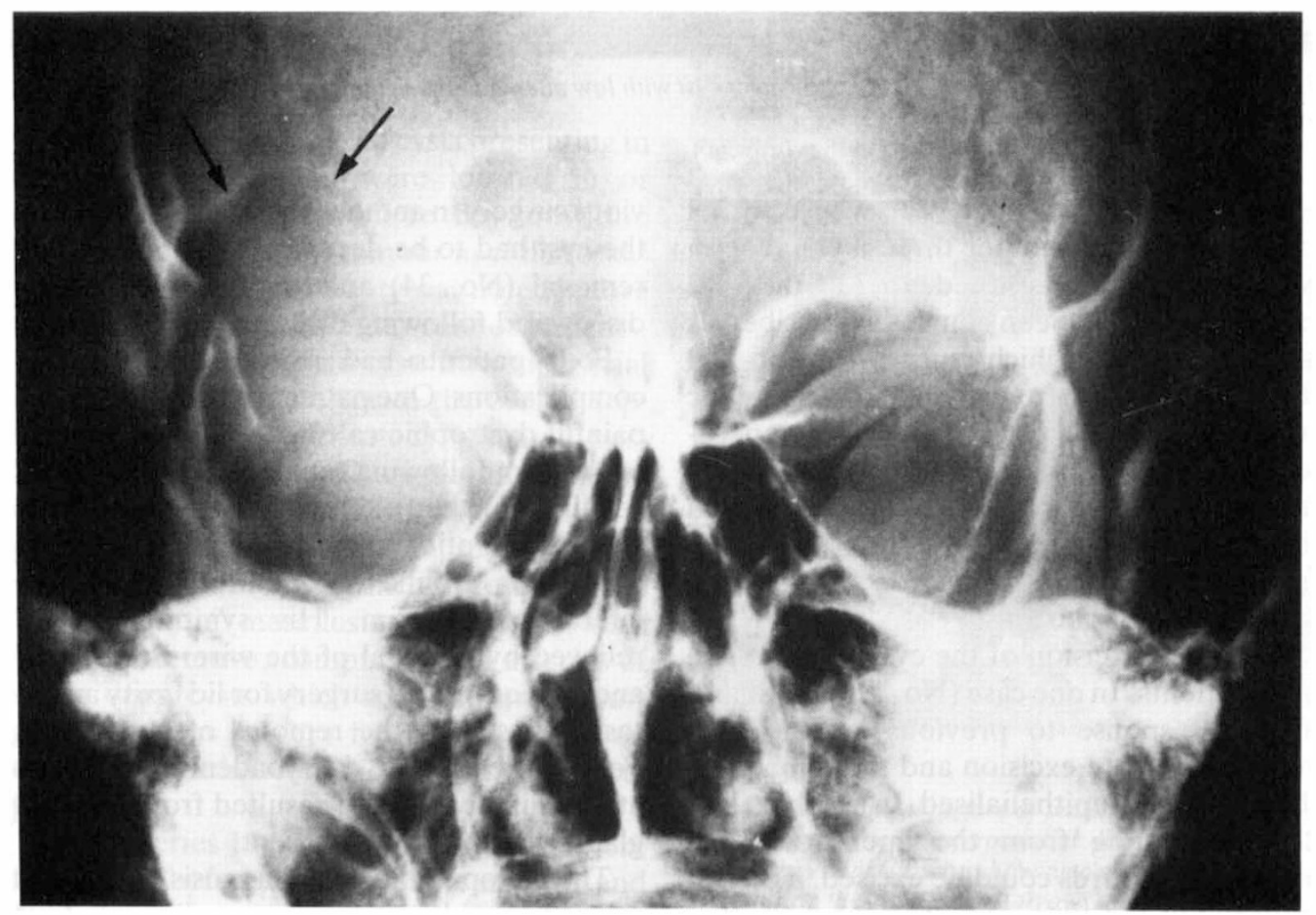

Fig. 2. PA skull X-ray of patient No. 40, showing erosion of bone (arrows) in the superior and lateral margins of the right orbit. 


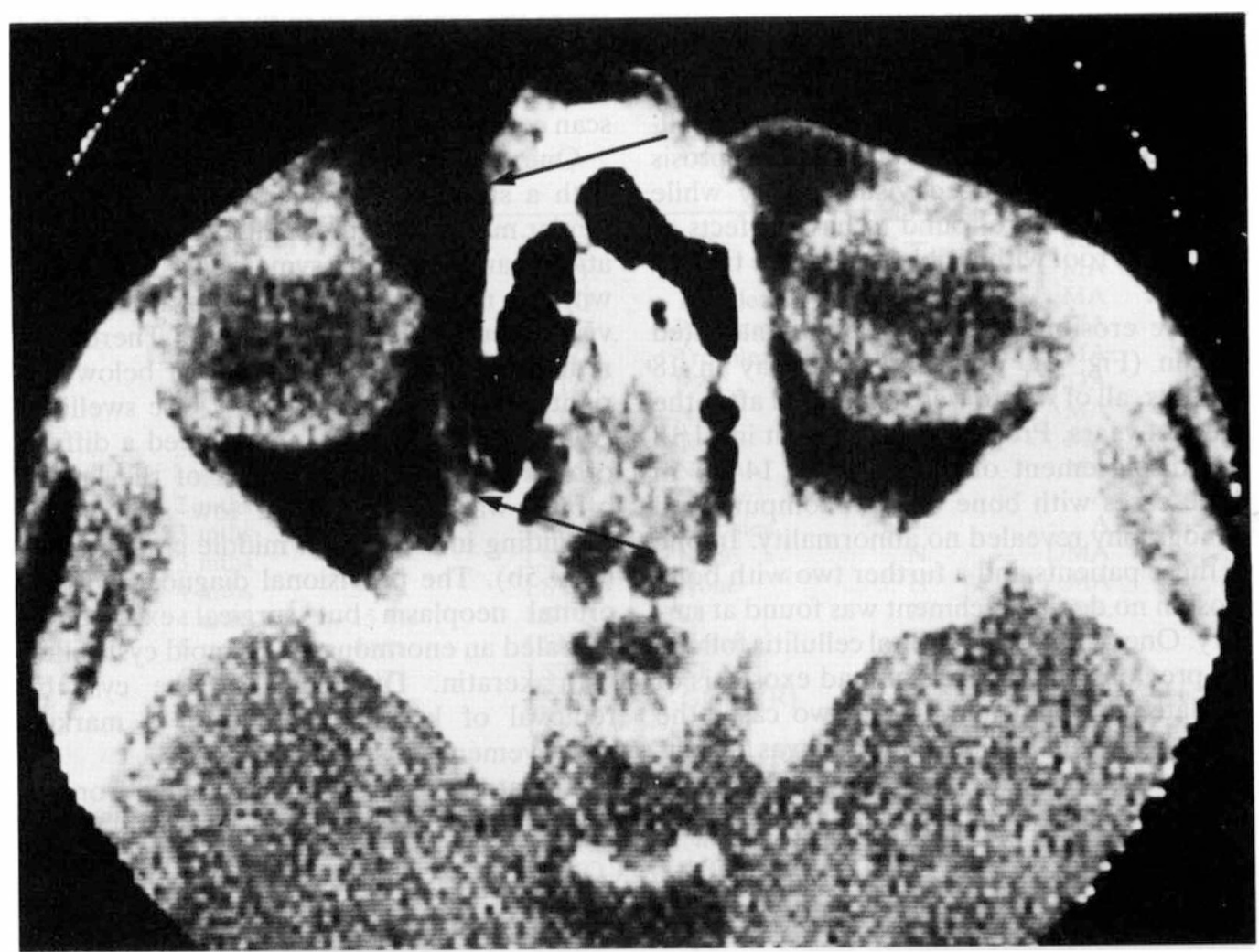

Fig 3. Axial CT scan of patient No. 30, showing a cyst with low attenuation originating from the left orbital apex (arrows).

No site of attachment of the cyst was recorded in 9 cases and in another three a connection with periosteum was noted. In 7 of these 12 cases the cyst had been clinically described as mobile. Eight, of which four were dumb-bell shaped, stemmed from the frontozygomatic suture, 3 from the lacrimal fossa or superotemporal rim, 2 from the lateral orbital wall, 2 from the roof, 4 from the orbital apex, 5 from the medial orbital wall, and 3 from behind the trochlea. One was attached to several areas, including the globe.

Complete excision of the cyst was possible in 37 patients. In one case (No. 17) the inflammatory response to previous surgery prevented complete excision and the remains of the cyst was de-epithelialised. In another (No. 27 ), originating from the apex, only the anterior two thirds could be excised. The cyst ruptured at the time of biopsy for suspected malignancy in one case (No. 39) and at pre- vious surgery in another two cases. In one case the cyst had to be decompressed to facilitate removal (No. 34) and small ruptures were discovered following excision in four cases.

Four patients had major post-operative complications. One patient (No. 6) developed painful dystrophic calcification of the lateral orbital rim following removal of bone, which required further exploration and excision a year later. Patient No. 25 developed a suture granuloma around one of the wires on the lateral orbital rim. His symptoms were relieved by removal of the wire. Patients 17 and 33 required lid surgery for lid laxity and ptosis, caused by the removal of large cysts. Four patients had dacryoadenitis and keratoconjunctivitis sicca resulted from lacrimal gland excision in one patient.

The histopathological diagnosis in 33 cases were dermoid cyst, in 3 cases conjunctival dermoid and in 4 cases epidermoid cyst. In 30 


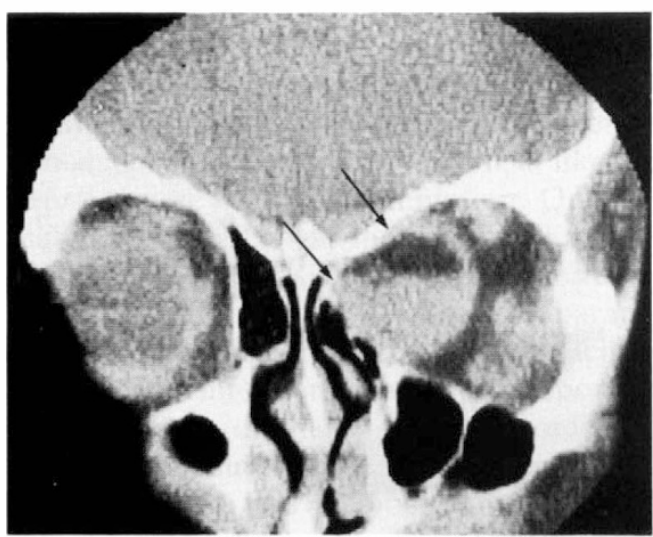

Fig 4. Coronal CT scan of patient No. 33, showing nasal cystic dermoid with a fluid level and indentation of the medial wall of the orbit (arrows).

cases there was a chronic inflammatory response, often with destruction of parts of the cyst wall (Fig. 6). All patients in whom cysts were noted before the age of 6 months had true dermoid cysts. Most conjunctival dermoids and epidermoid cysts presented later than dermoids. Three of the four epidermoid cysts had cranial involvement.

\section{Discussion}

In a large series of dermoid cysts presenting in children, 37 per cent were located in or around the orbit, ${ }^{6}$ a site where they constitute the commonest orbital tumour in childhood. ${ }^{7}$ In this series an abnormality was noted before the age of 12 years in 75 per cent of patients. Grove $^{5}$ divided dermoid cysts into superficial (simple), located anterior to the orbital septum and deep (complicated), situated posterior to the septum. Deep dermoids often cause ocular displacement and non-axial proptosis. Sherman ${ }^{8}$ found that seven cases of superficial dermoids which presented as 'asymptomatic' mass lesions in infants were simple to remove, compared with a series of seven deep cysts which required major surgery. Previous surgery for five of the seven deep dermoids complicated the clinical picture.

In this series 11 of the 13 mobile cysts were first noted before the age of six months and were clinically superficial, but one mobile cyst (No. 31) which was noted at the age of 13 years extended to the orbital apex. Bone erosion was only found in three (19 per cent) of the 16 patients in whom a cyst was noted before 6 months of age but 14 (74 per cent) of the 18 patients in whom the cyst was noted after the age of 3 years. The distinction between superficial and deep cysts was not always clear. For example, ocular displacement or bone erosion featured in some patients in whom no deep attachment was found at surgery. The direction of ocular displacement, most commonly downwards, was influenced by involvement of the superior orbit alone in 92.5 per cent of cases.

An orbital X-ray was useful for determining the extent of involvement of bone, but computerised tomography revealed the site of

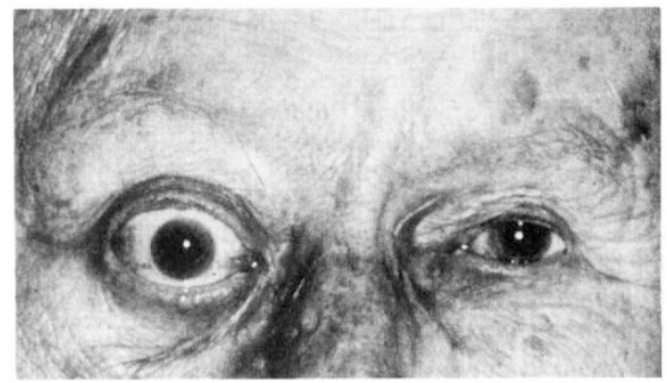

Fig. 5(a)

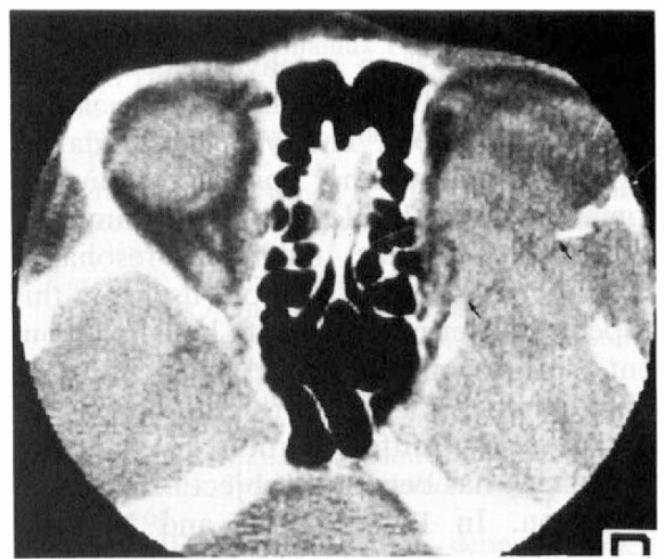

Fig. 5(b)

Fig. 5. (a) Clinical picture of patient No. 40, showing right proptosis with inferomedial displacement of the globe. (b) Axial CT scan showing an extensive defect in the wall of the right orbit (arrows) and a lesion with areas of low attenuation, initially interpreted at necrotic tumour. 


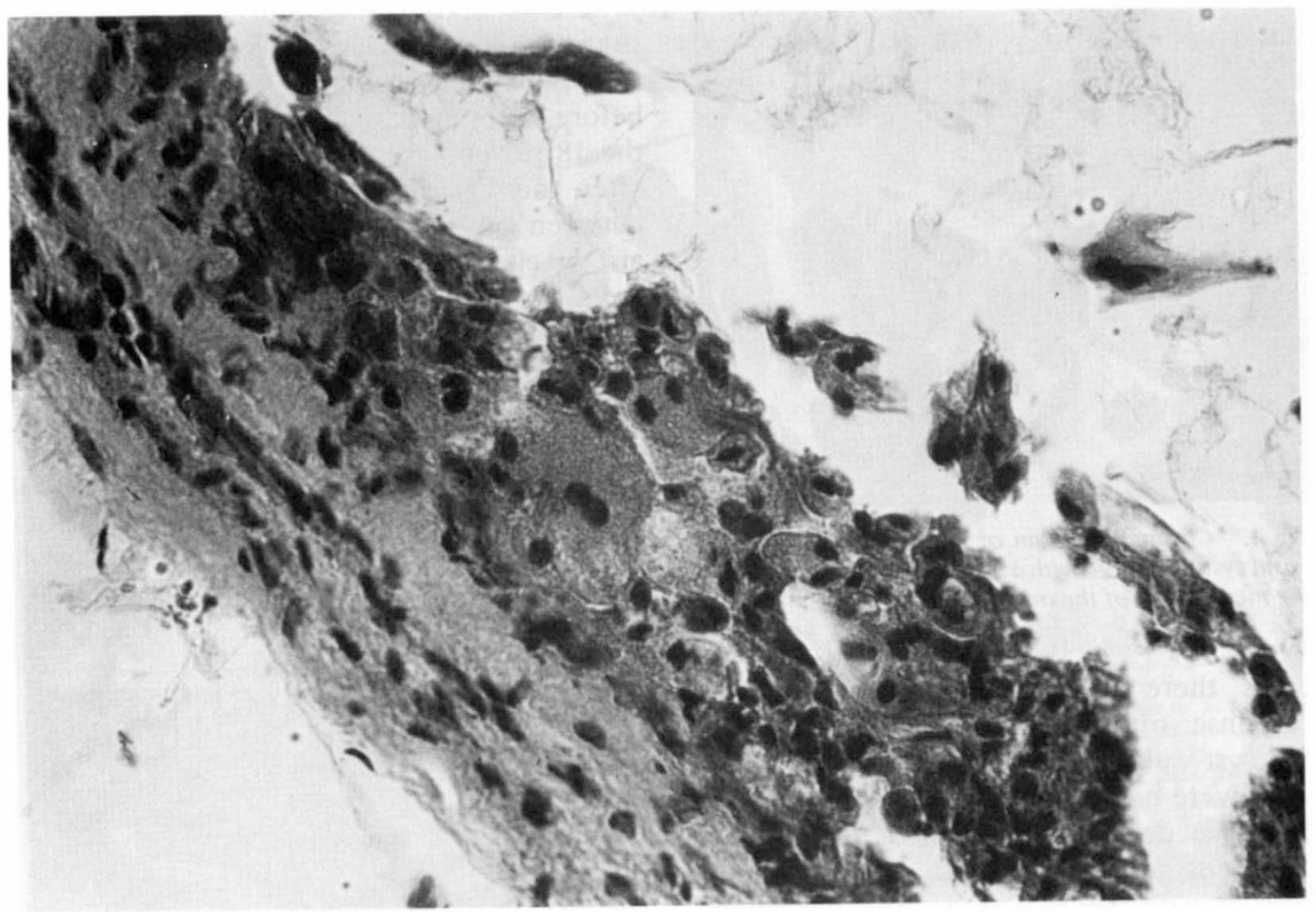

Fig. 6. Light micrograph taken at higher power of an H\&E stained section of part of the wall of a dermoid cyst from patient No. 19. In this area the epidermis has been completely replaced by a chronic inflammatory infiltrate with some giant cells.

attachment in selected cases. The attenuation coefficient varied from uniformly low in lipidfilled dermoids ${ }^{9,10}$ to patchy areas with the same Hounsfield values as brain in the case of a large epidermoid. The type of attenuation appears to reflect either lipid of keratin predominance and the degree of inflammatory response. ${ }^{11}$ Nuclear magnetic resonance imaging may prove even more useful in this respect. ${ }^{12}$ A dermoid cyst with high lipid content typically appears white in the short $T_{1}$ weighted image, as does orbital fat.

Historically, differentiation of types of orbital cyst has been the subject of repeated discussion. In 1948 Pfeiffer and Nicholl ${ }^{13}$ reviewed the subject and presented a series of 9 cases of deep orbital cysts. Several showed cholesterol crystals, two were epithelial lined, one contained keratin and most were inflamed. Inflammation could result in bleeding into a cyst and the wall of an epidermoid cyst could become unrecognisable. This lesion would be indistinguishable from the 'haematic' or 'cholesterol' cyst which is sometimes attributed to trauma. In contrast, dermoids may be identified by adnexal features.

The association of epidermoid cyst with late presentation and cranial involvement is striking. This trend may have been obscured by clinical use of the term 'dermoid' to encompass both dermoid and epidermoid cysts. Carey, ${ }^{14}$ in 1959 , presented 7 cases from the National Hospital, Queen Square, of which 5 were epidermoids and only two were dermoids. He quoted Bostroem's observation that 'the difference depended not only on the actual depth, but also on the embryonic antiquity of the rest, and that a younger and more primitive layer would have the characteristics of dermoid rather than an epidermoid growth'. If this was true one would expect dermoids to be deeper. However it may be invagination of ectodermal hair buds by suitable mesoderm which is essential for forma- 
tion of adnexal structures, as it is in normal skin. ${ }^{15}$ This would be consistent with the deeper location of most epidermoid cysts.

Marsupialisation has been recommended for deep and large cysts, ${ }^{16,17}$ but is likely to cause severe orbital inflammation. Only one case in the series was marsupialised and the epithelial lining was removed. The area of the cyst was irrigated, but no steroid preparation was used because of the grave risk of facilitating orbital infection. There are reports of spontaneous discharge of dermoid cysts through a sinus, ${ }^{18,19}$ but the two cases described here had previous surgery.

\section{Conclusions}

In most cases the diagnosis of an orbital dermoid was made prior to surgery on the basis of the position and consistency of the cyst and typical appearances on X-ray or CT scan. Two cases simulated a malignant tumour. ${ }^{20}$ Epidermoid cysts showed a tendency towards cranial involvement. Most cysts had associated leakage with inflammation, which was most severe in cases involving the lacrimal gland and those who had undergone previous surgery. Pain was always associated with inflammation but the converse was not true.

Mobile cysts noted before the age of 5 months and not associated with proptosis could be excised intact through an anterior orbitotomy. Two patients had strabismus which may have been related to the cyst. All patients in whom the lesion was noted after the age of three had deep cysts which affected visual or oculomotor function.

Orbital dermoids or epidermoids should be excised because they enlarge and the contents leak into adjacent tissues. The material within these cysts is highly irritant and provokes a severe inflammatory reaction, often followed by fibrosis. The cysts should be excised in their entirety, where possible, using a surgical approach which gives good access to all parts of the lesion. If the patient is a child and the cyst is very extensive, so that removal of bone is essential to dissection, then surgery should be delayed until bone growth has ceased.

The authors would like to thank Professor A. Garner for reviewing the histopathology and Dr.
Alison McCartney for the micrographs and staff in the Departments of Medical Illustration and Radiology at Moorfields Eye Hospital for their contribution.

\section{References}

${ }^{1}$ Batsakis JG: Teratomas of the head and neck. In tumours of the head and neck. Clinical and pathological considerations. Williams and Wilkins Co. 1974. 155-161.

${ }^{2}$ Brownstein MH and Helwig EB: Subcutaneous dermoid cysts. Arch Dermatol 1973; 10: 237-9.

${ }^{3}$ Jakobiec FA, Bonnano PA, Sigelman J: Conjunctival adnexal cysts and dermoids. Arch Ophthalmol 1978; 96: 1404-9.

${ }^{4}$ Shields JA, Augsburger JJ, Donoso LA: Orbital dermoid cyst of conjunctival origin. $A m J$ Ophthalmol 1986; 101: 726-9.

${ }^{5}$ Pollard ZF, Harley RD, Colhoun J: Dermoid cysts in children. Pediatrics 1976; 57: 379-82.

${ }^{6}$ Nicholson DH, Green WR: Tumors of the eye, lids and orbit. In Harley RD ed. Pediatric Ophthalmology. Philadelphia, WB Saunders \& Co. 1975; 1001 .

${ }^{7}$ Grove AS Jr: Orbital disorders: diagnosis and management. In McCord CD Jr. ed. Oculoplastic surgery. New York: Raven Press 1981: 274277.

${ }^{8}$ Sherman RP, Rootman J, LaPointe JS: Orbital dermoids: clinical presentation and management. $\mathrm{Br}$ J Ophthalmol 1984; 68; 642-52.

${ }^{9}$ Wright JE, Lloyd GAS, Ambrose J: Computerised Tomography in the detection of orbital space occupying lesions. Am J Ophthalmol 1975; 80: 78-81.

${ }^{10}$ Blei L, Chambers JT, Liotta LA, Di Chiro G: Orbital dermoid diagnosed by computed tomographic scanning. Am J Ophthalmol 1978;85: 58-61.

${ }^{11}$ Moseley IF and Sanders MD: Compterised Tomography in neuro-ophthalmology. London: Chapman and Hall 1982; 59.

12 Zimmerman RA, Bilaniuk LT, Yanoff M, Schenk JF, Hart HR, Foster TH, Edelstein WA, Bottomley PA, Redington RW, Hardy CJ: Orbital magnetic resonance imaging. Am J Ophthalmol 1985; 100: 312-7.

${ }^{13}$ Pfeiffer RL and Nicholl RJ: Dermoid and epidermoid tumours of the orbit. Arch Ophthalmol 1948; 40: 639-64.

${ }^{14}$ Carey PC: Epidermoid and dermoid tumours of the orbit. Br J Ophthalmol 1958; 42: 225-39.

${ }^{15}$ Warwick R and Williams PW eds. Gray's Anatomy. 35th Edition Norwich: Longman 1973: 125.

${ }^{16}$ Grove AS: Giant dermoid cysts of the orbit. Ophthalmology 1979; 86: 1513-20.

${ }^{17}$ Kennedy RE: Marsupialization of inoperable orbital dermoids. Trans Am Ophthalmol Soc 1970; 68: 146-64.

${ }^{18}$ Cullen JF: Orbital diploic dermoids. $\mathrm{Br} J$ Ophthalmol 1974; 58; 105-6.

${ }^{19}$ Pollard ZF and Calhoun J: Deep orbital dermoid with draining sinus. Am J Ophthalmol 1975; 79: 310-13.

${ }^{20}$ MacDonald $\mathrm{R}$ and Byers J: Dermoid tumour simulating a neoplasm. Am J Ophthalmol 1959; 47: 863-6. 